\title{
Water Quality Zoning Based on Water Quality Index and Wilcox Index Using Geographic Information System
}

\author{
Ghodratola Khoramabadi Shams ${ }^{1}$; Abdolrahim Yusefzadeh ${ }^{2,}$; Hatam Godini ${ }^{1}$; Edris \\ Hoseinzadeh $^{3}$; Mohammad Khoshgoftar ${ }^{4}$ \\ ${ }_{2}^{1}$ Department of Environmental Health, School of Health, Lorestan University of Medical Sciences, Khorramabad, IR Iran \\ ${ }^{2}$ Young Researchers and Elite Club, Sardasht Branch, Islamic Azad University, Sardasht, IR Iran \\ ${ }^{3}$ Department of Environmental Health, Faculty of Medicine, Tarbiat Modares University (TMU), Tehran, IR Iran \\ ${ }^{4}$ Vice-Chancellery of Health, Shahroud University of Medical Sciences, Shahroud, IR Iran \\ ${ }^{*}$ Corresponding author: Abdolrahim Yusefzadeh, Young Researchers and Elite Club, Sardasht Branch, Islamic Azad University, Sardasht, IR Iran. Tel: +98-9143425434, Fax: +98- \\ 4444375585, E-mail: ryusefzadeh@yahoo.com \\ Received: April 5, 2014; Revised: June 1, 2014; Accepted: June 1, 2014
}

\begin{abstract}
Background: Due to the limited fresh water resources and its important role in life and progress of nations, maintaining the water quality is necessary.

Objectives: The purpose of this study was to evaluate quality of Khorramrood River water using Indexes of water quality including water quality index (WQI) and Wilcox and zoning with geographical information systems (GIS).

Patients and Methods: In this cross-sectional study, the quality parameters required for the calculation of quality indicators, i. e. WQI and Wilcox index, were measured by using standard methods at six selected stations during six months in 2012. This Parameters consisted of $\mathrm{pH}$, dissolved oxygen, total dissolved solids, electrical conductivity, biochemical oxygen demand, turbidity, temperature, phosphate, nitrate, fecal coliform, calcium, magnesium, and sodium. River zonation was done using the software GIS.

Results: By using WQI, the best water quality was reported in station number one with the scalar quantity of 71.11 (water with best quality) and the worst water quality was in station number six with scalar quality of 42.77 (water with bad quality). By using a Wilcox index for agricultural consumption, the river water based on EC classified in C2 and C3, and based on SAR it classified in S4. The quality parameters concerning the total dissolved solids, turbidity, nitrate, phosphate, and BOD5 in some sampling stations were higher than standard limit of surface water.

Conclusions: According to the average of WQI index, quality of water was good in station number one, medium in station number two, and bad in the rest of stations. According to the WILCOX Index, qualities of water in third station were medium and in the rest were good.

Keywords: Water Quality; River; Geographic Information Systems
\end{abstract}

\section{Background}

Rivers are one of the vital arteries for humans survival that have always had a significant role in the genesis and development of human societies $(1,2)$. River are the major source of water supply for various applications including agriculture, industry, and drinking. Therefore, monitoring the quality of these resources due to the recent drought and urban and rural development is one of the major tasks in the field of environment (3). The water quality is considered a key element of the sustainable use of agricultural land (4). The water quality data are essential to enforce water quality laws and to determine the pollutants to protect human health as well as ecosystems (5). The Surface water quality is critical issue and is beyond the boundaries of nations; it is influenced by factors including atmospheric chemistry, layers below the soil surface, plants (or decomposed organic matter), and abnormal agents (6). Soil and water are in direct contact with each other and the possible contamination in each section would be transferable to other sectors. Therefore, to prevent complications in the agricultural area, evaluating the water quality resources to irrigate fields and orchards seems necessary (7). Water is the most important issue after agricultural fertilizers; if the water is polluted, it can be dangerous for plants, animals, and even humans (8). The ability of water for agriculture not only will determine the total percentage of salt in the water but also can specify types of salt. Water of Capability for agriculture will determine total percentage of salt and various salts in water (9). The use of water quality index (WQI) is very prevalent and is a comprehensive index for surface water quality classification $(10,11)$. WQI is a very useful and efficient method for assessing the suitability of water quality (12). Gatot et al. considered quality indexes including sanitation foundation water quality index (NSFWQI) and WQI as the best indexes for monitoring the quality of surface water in Malaysia and Indonesia (13). Dadollahi and 
Arjmand examined the quality of water in Karoon River for ten consecutive month at three sampling stations by using the WQI index; in their study, plant effluent entering the river was the main cause of reduced quality of water (14). In addition, Yusefi et al. used WQI index for checking the quality of Sefidrood river in 2007-2008 and reported the quality ranging from bad to favorable (15). Hajian Nejad et al. assessed the qualitative parameters of water from Zayandeh rood River; the cause of declining water quality was entering effluent of refinery into the river (16). Ahmadi-Mamaqani et al. evaluated the physical and chemical parameters to determine water quality in Tajen river and showed high phosphate and ammonia concentration in the water (17). Wilcox diagram is one of the methods for the classification of surface water for agricultural purposes. It was introduced by the Ministry of America Agriculture. This classification was presented in 1948 by Wilcox and three years later was completed by Toren. Today, this index is considered a common method of water classification for agricultural purposes $(7,18)$. The two factors of electrical conductivity (EC) and sodium adsorption ratio (SAR) are considered and each of them is converted into four parts that totally create 16 groups. Index of Wilcox is representative of SAR and C is representative of EC and finally, the water quality is classified into four categories in terms of agricultural purposes (7). During the study of flowing rivers in the plains of Hamadan by Wilcox index in the 2008 , Rahmani et al. showed the water quality as the medium and good class for irrigation in sampled rivers (8). During a case study on Mahandy river in India in 2001-2003, Sundaray et al. studied the river quality for readiness to agricultural purposes in six different period at 31 stations; by mathematical relations. They calculated parameters such as SAR, residual sodium carbonate, magnesium levels in soil, and water permeability in order to determine the water suitability for agricultural purpose that results were consistent with the Wilcox diagram. Based on Wilcox index, samples from all different areas were in excellent to good class (low to moderate salinity with low sodium) that was suitable for all soils and salt-sensitive crops (19). Khorramrood River, called "Gelall" in the native language, is part of Karkheh Basin and is originated from the northern heights of the city and the slopes of the Sefid Mountains and Kamarsyah
Mount and is Located in the middle of Khorramabad city. Instead being the source of beauty and purity, nowadays its condition is completely catastrophic and unhygienic and threatens the health of local people. Unfortunately, no effective action has been taken in this regard yet. After passing through north villages, where it is used for agriculture, it enters the city and contaminates the water with a lot of pollutants such as industrial and domestic waste water, agricultural pesticides, and fertilizers. Another use of water is for industry part and the Green Spaces of Khorramabad city. The total length of the river is $110 \mathrm{~km}$ with about $5 \mathrm{Km}$ passing through the city of Khorramabad (20). The average and maximum of monthly flow of the water in 55 years ago in Khorramabad were 10.14 and $28.721 \mathrm{~m}^{3} / \mathrm{s}$, respectively. The change of seasons in the rivers water have been significant during the year and its depth changes from 40 to $100 \mathrm{~cm}$ in some places (20).

\section{Objectives}

In this study the water quality of river was checked based on WQI and Wilcox indexes and was zoned by use of Geographic Information System (GIS). Depending on the degree of water quality, the source of potential contamination was identified in the different sampling stations so that the appropriate action might be taken in the subsequent studies or administrative interventions by concerned organizations.

\section{Materials and Methods}

In this cross-sectional study, samples were collected in six consecutive months and once a month based on standardized and tested methods. The numbers of sampling stations was six and there were 14 qualitative parameters for each station. Tests were repeated twice for each parameter. The total numbers of the Analyzed samples was 936.

\subsection{Determination of the Study Site and Sampling Stations}

The Khorramrood River is part of Karkheh catchmnet area and drains the northern part of this basin, Kakasharaf River and southeast of it. These two rivers combine near

\begin{tabular}{|c|c|c|c|c|}
\hline & \multicolumn{4}{|c|}{ Coordinates of the Stations Studied } \\
\hline & Mark & UTM_Y & UTM_X & Height, $\mathrm{m}$ \\
\hline The river originates in the Khorramrood above the village of Robat Namaky & A & 3722520 & 249106 & 1521 \\
\hline Lower than the Cham Chaghal village or Gorzayn & B & 3726669 & 249472 & 1519 \\
\hline Lower than Sand Workshop, Mavlavi sand and Ghaleh Sangi village & $\mathrm{C}$ & 3716933 & 249692 & 1517 \\
\hline Into Khorramabad city under Shohadah bridge & $\mathrm{D}$ & 3708457 & 254345 & 1517 \\
\hline Output of Khorramabad & E & 3704357 & 250803 & 1515 \\
\hline Lower than Khorramabad Airport & $\mathrm{F}$ & 3704173 & 247311 & 1513 \\
\hline
\end{tabular}




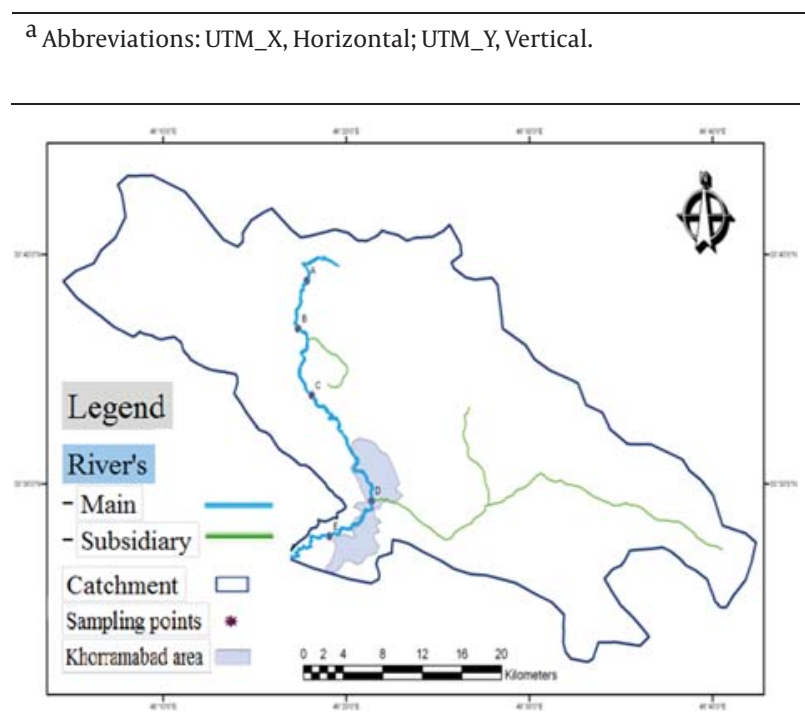

Figure 1. Location of Sampling Sites in Khorramrood River of Khorramabad

the strait of continuous output than passed through the middle of Khorramabad River and will be entered into Kashkan. After studying the river path carefully by the map of the river path, we identified the total position of river with scale of 1:50000. Then we determine the location of stations under study according to the relevant branches and location of pollutant factories as well as the location and the possibility of contaminants entering the river water. Samples as presented in Table 1. A schematic of the sampling locations are shown in Figure 1.

\subsection{Sampling and Test Specimens}

Samples were collected from the stations selected according to standard methods (21) at the 15th day of six consecutive months during the summer and autumn of 2012. Harvesting, transport, storage and testing of samples were performed consecutively by standard methods. Factors affecting the quality of sample including sample contamination, pollution, equipment, sample sizes, and the time interval between the collection, transfer, and transportation to the laboratory conditions were considered. Parameters of the physical, chemical, and biological tests included: DO, pH, total dissolved solids (TDS), biochemical oxygen demand $\left(\mathrm{BOD}_{5}\right)$, turbidity, temperature, conductivity, phosphate, nitrate, fecal coliform, calcium, magnesium, sodium, temperature, conductivity, dissolved oxygen, and $\mathrm{pH}$ were measured at the sampling site. The ratio of EC and temperature were measured using the EC-meter (model AQUA-COND, made in Germany), Dissolved oxygen by DO-meter (model wtw Oxi 330/SET, made in Germany), and $\mathrm{pH}$ by a pH-meter (model $\mathrm{pH} 230$ SensoDirect, made in Germany). Turbidity of samples was determined using the turbidity-meter (model $2100 \mathrm{~N} \mathrm{HACH}$, made in
Germany). TDS was determined according to the standard method (number 2540 ) at $105^{\circ} \mathrm{C}$ to $103^{\circ} \mathrm{C}$ and according these, were determined the (TDS). BOD $_{5}$ was determined by standard procedures and was read using model $\mathrm{BOD}_{5}$ incubator (model BOD II TRACK 2100, German HACH Co. Germany). Cadmium reduction method (method 8039 provided by HACH Co., Germany) for measuring nitrate spectrophotometer DR-5000 was used in nine steps. Total phosphate by spectrophotometer DR-5000 and the ascorbic acid method (method 4048 provided by HACH Co., Germany) by standard method 4500-PE USEPA were measured in the seven stages. Fecal coliform was calculated in $100 \mathrm{ml}$ of the sample with membrane filter standard method using a strainer pour of $45 \mathrm{ml}$ /Millipore Vacuum Pump and zero micron and incubator to culture (model IKA KS 4000 Incubator Shaker, made in Germany). Total hardness, calcium and magnesium were measured by standard method (titration method). Sodium was measured using Flame Photometer Model 405C clinical flame photometer at a wavelength of $589 \mathrm{~nm}$. Sodium absorption ratio was calculated using Equation 1.

Equation 1.

$$
\mathrm{SAR}=\frac{\mathrm{Na}}{\sqrt{\frac{\mathrm{Ca}+\mathrm{Mg}}{2}}}
$$

\subsection{Calculation Index}

WQI has been used for evaluating rivers pollution and shows combined effects of physicochemical and biological parameters according to the Equation 2 (22). This pattern was used for the first time by NIH of the United States for water quality monitoring (22).

Equation 2.

$$
\mathrm{WQI}=\sum W_{i} Q_{i}
$$

Where WQI is water quality index with values ranging from 0 to 100 ; Wi is the weight or the priority level of zero to one (Table 2); and Qi is the parameters quality from 0 to 100 (Table 3 ).

In this software, obtained data were according to priority level or weight of every parameter in Table 2 and 3 ; the information was extracted from combined standard curves. WQI system needs to provide a definite association between the experimental values and the quality of each feature that can give a characteristic to water. Since the water is not a measurable unit, making this association needs a qualitative inference (9). The 
determination mechanism of this association was use of standard curves and table index. Thus we could examine the water quality in some stations from river in some periods.

Table 2. Demanded Parameters and Chosen Weight for the System of Water Quality Index in Rivers ${ }^{\mathrm{a}}(15)$

\begin{tabular}{|c|c|}
\hline Parameters & Weight \\
\hline Dissolved oxygen, \% Saturation & 0.17 \\
\hline Fecal coliform, Colony/100 mL & 0.16 \\
\hline pH & 0.11 \\
\hline BOD5, mg/L & 0.11 \\
\hline Temperature, ${ }^{\circ} \mathrm{C}$ & 0.10 \\
\hline Total phosphate, mg/L & 0.10 \\
\hline Nitrate, mg/L & 0.10 \\
\hline Turbidity, NTU & 0.08 \\
\hline Total dissolved solids, mg/L & 0.07 \\
\hline
\end{tabular}

a Abbreviation: $\mathrm{BOD}_{5}$, biochemical oxygen demand.

Table 3. The Classification of Water Quality Index Based on the Color and Quality of Numerical Values (15)

\begin{tabular}{lcc}
\hline & $\begin{array}{c}\text { The Interpretation of the Nu- } \\
\text { merical Value of the Index }\end{array}$ & $\begin{array}{c}\text { The Value of } \\
\text { Numerical }\end{array}$ \\
\hline Red & Terrible & $0-25$ \\
Orange & Bad & $26-50$ \\
Yellow & Average & $51-70$ \\
Green & Good & $71-90$ \\
Blue & Top & $91-100$ \\
\hline
\end{tabular}

\subsection{Calculation of Wilcox Index}

Regardless of the danger of disintegration, important cations in terms of water use in agriculture include calcium, magnesium, sodium, and most of the other ions in the soil. SAR is commonly used to predict soil permeability problems through Equation 1 in which all cations are expressed in meq/L (7).

To calculate this index, the EC was scaled on the horizontal axis and the SAR on the vertical axis of the diagram. Then we extended that point to other areas to cut on the spot and based on this point, which can be located in any part of the diagram, the water quality could be determine based on this index (7). This index represents SAR and C represents EC, which represent the quality of water for agriculture in the four categories that include very good (C1S1), good ( $\mathrm{S} 1 \mathrm{C} 2, \mathrm{~S} 2 \mathrm{C} 2$, and $\mathrm{S} 2 \mathrm{C} 1)$, medium (C1S3, C2S3, C3S1, C3S2, and C3S3), and bad classes (C4S1, C4S4, C3S4, C2S4, C1S4, C4S2, and C4S3) (Table 4).

\subsection{Preparing Maps and River Zonation}

Firstly, the sampling stations were chosen and then were harvested with the GPS receivers Oregon 550 model that was taken XYZ with UTM format. After removing of the coordinate, the final conversion on data was performed by the GIS software with providing output like GIS maps with for- mat of point; the sample point of description table was updated in the next phase. GIS has been widely used in water and environment applications and many efforts have been made for applying GIS to resource and environment management (25). For analyzing, the Excel software was used.

Table 4. Classification of Surface Water for Agriculture Based on Sodium Adsorption Ratio, Electrical Conductivity, Total Dissolved Solids, and Total Hardness ${ }^{\mathrm{a}}(23,24)$

\begin{tabular}{|c|c|}
\hline Quality Parameters & Water Class \\
\hline \multicolumn{2}{|l|}{ SAR } \\
\hline$<10$ & Top (S1) \\
\hline $11-18$ & Good (S2) \\
\hline $19-26$ & Average (S3) \\
\hline$>27$ & $\operatorname{Bad}(\mathrm{S} 4)$ \\
\hline \multicolumn{2}{|l|}{$\mathbf{E C}, \mu \mathbf{s} / \mathbf{c m}$} \\
\hline $100-250$ & Top (C1) \\
\hline $251-750$ & Good (C2) \\
\hline $751-2250$ & Average (C3) \\
\hline$>2251$ & $\operatorname{Bad}(\mathrm{C} 4)$ \\
\hline \multicolumn{2}{|l|}{ TDS, mg/L } \\
\hline$<1000$ & Fresh water \\
\hline $1001-3000$ & A little salty \\
\hline 3001-10000 & Average salinity \\
\hline $10001-30000$ & Very salty \\
\hline \multicolumn{2}{|l|}{ TH, mg/L } \\
\hline$<75$ & Soft \\
\hline $76-150$ & Medium Difficulty \\
\hline $15-300$ & Hard \\
\hline$>301$ & Very Hard \\
\hline \multicolumn{2}{|l|}{ pH } \\
\hline $6.5-8.4$ & Common area \\
\hline
\end{tabular}

a Abbreviations: C, Salinity Hazard; C1, Salinity Hazard (Class: Low); C2, Salinity Hazard (Class: Medium); C3, Salinity Hazard (Class: High); C4, Salinity Hazard (Class: Very High); EC, electrical conductivity; SAR, sodium adsorption ratio; S, Sodium (Alkali) Hazard; S1, Sodium (Alkali) Hazard (Class: Low); S2, Sodium (Alkali) Hazard (Class: Medium); S3, Sodium (Alkali) Hazard (Class: High); S4, Sodium (Alkali) Hazard (Class: Very High); TDS, total dissolved solids; TH, Total Hardness.

\section{Results}

According to Figure 2, the quality of water in July was average and in other months was bad.

According to Figure 3, water quality was good in station one, medium in station two, and bad in other stations.

Based on WQI, the best quality of rivers water in station and in studied months were respectively in station one $(\mathrm{WQI}=77.11)$ and July $(\mathrm{WQI}=50)$ and the worst quality in 
station and in studied months were respectively in station six (WQI = 42.77) and September (WQI = 45.55). The more we moved from the station one toward the last stations, the more the quality reduce and the WQI declined. The zoning of the water quality of Khorramrood River of Khorramabad based on WQI by GIS is shown in Figure 4. According to the zoning of station number one, the green color indicates good water quality, the Yellow color of second station indicates the medium quality, and the orange colors show the bad quality of water in other stations.

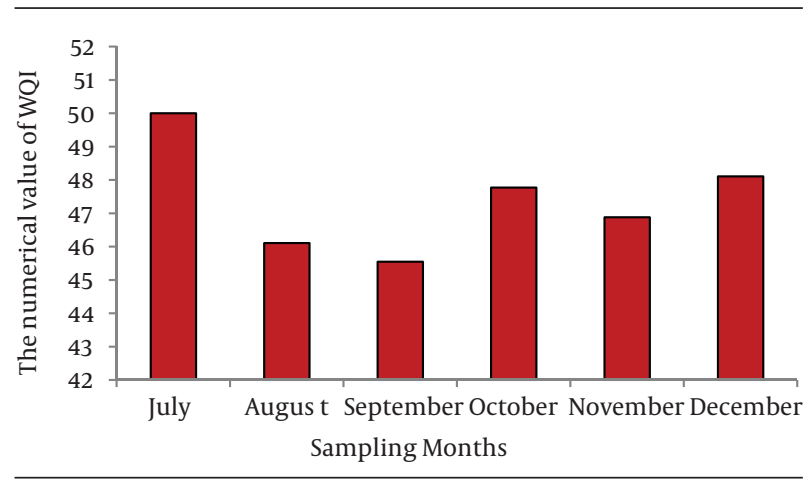

Figure 2. Average Water Quality Index in Studied Months

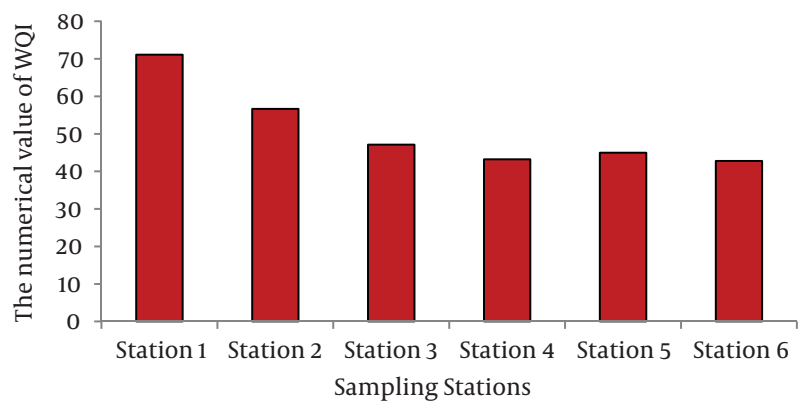

Figure 3. Average Water Quality Index at Stations Studied

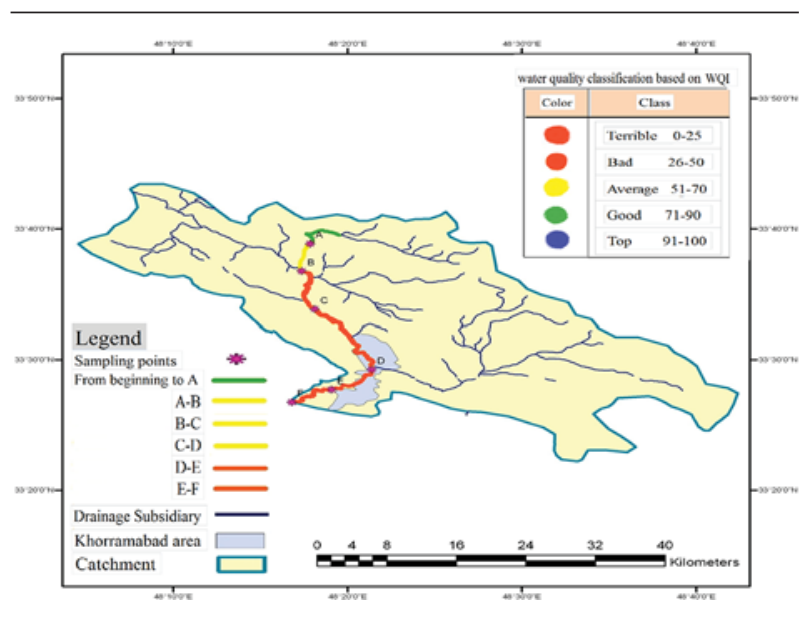

Figure 4. The Zoning of Khorramabad River Water Quality Based on the Average of the Water Quality Index During the Study Period

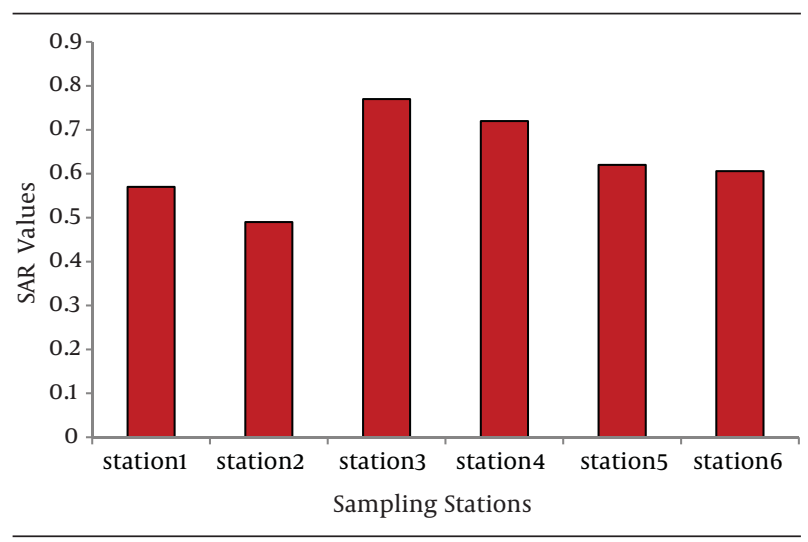

Figure 5. The Average Sodium Adsorption Ratio in the Studied Stations

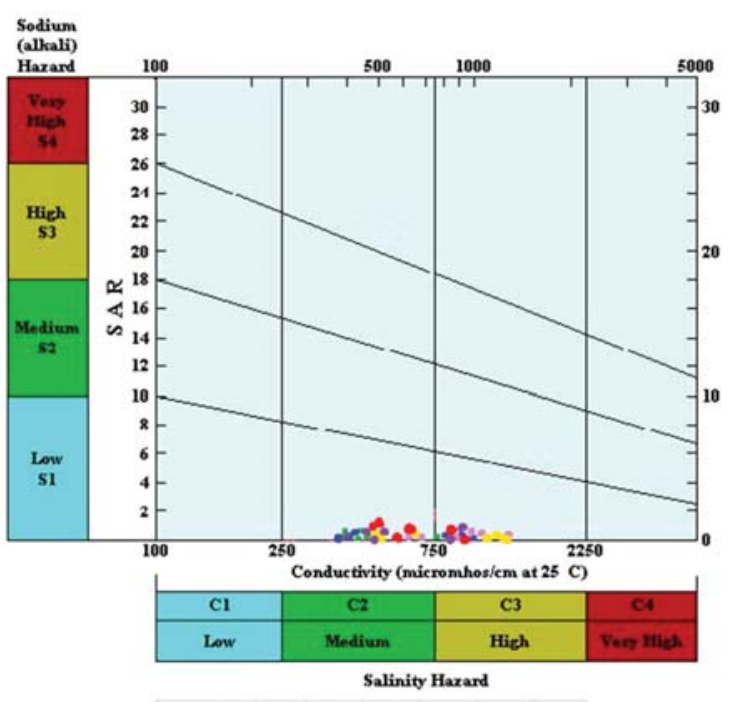

Stations A: $\bullet$ B: $\bullet$ C: $\bullet$ D: $\bullet$ E: $\bullet$ F:

Figure 6. The Classification of the River Water Based on the Wilcox Diagram in Studied Stations

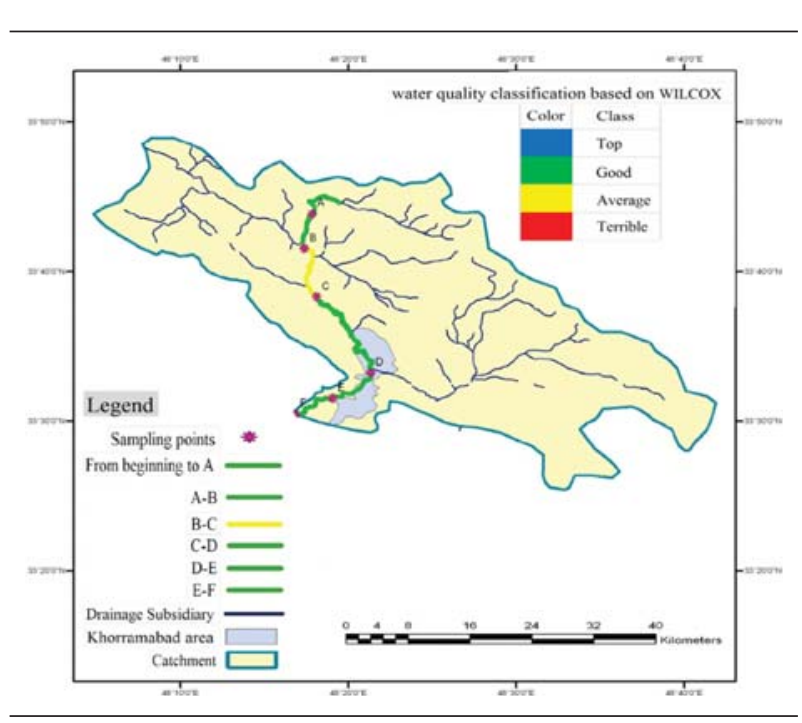

Figure 7. The Zoning of the Class Water Quality Base on Wilcox Index 
According to the performed tests in the sampled stations and in the months of study, the lowest ratio of the EC related to station number two on August (423.5 $\mu \mathrm{s} / \mathrm{cm})$ and the highest ratio related to station three on October $(1081 \mu \mathrm{s} / \mathrm{cm})$. The highest and lowest ratio of SAR stations related to station two and three. The classification of water quality for agriculture based on EC, the river water was placed in the Class of $\mathrm{C} 2$ and $\mathrm{C} 3$. Based on the results of the calculations of SAR, the river water quality was placed in the class of S1 (Figure 5).

The distribution of point in the Wilcox index showed that $66.41 \%$ of samples of the different stations were located in the area of $\mathrm{C} 2 \mathrm{~S} 1$ and other $34.58 \%$ in the area of C3S1 (Figure 6).

The class zoning of the river water quality based on Wilcox index for agricultural purposes showed that the river water quality at station three was average, which is shown with the yellow color. Stations with good water quality are marked with green color (Figure 7).

\section{Discussion}

Many factors affect the water quality of this river. These factors are various in the different sites. The combination of the rain water, chemicals of soil, minerals of soluble stone, and the human activity are the main factors that determine the quality of river water in each location (26). The zoning of the river water quality of Khorramrood River of Khorramabad, based on WQI index using a GIS system, showed that unlike other stations, the water stations number one had good quality in all of the studied months. The reasons was lack of entering human sewage, industrial effluent, agricultural pollution, and other pollutant factors. The water quality was average in the station Number two during all the months. The reasons of the declining of the water quality in the second station was high concentrations of total dissolved solids, fecal coliform, and $\mathrm{BOD}_{5}$. Water quality was poor in the rest of the stations. The reasons of decline in water quality in these stations were urban and rural sewage agriculture runoff, domestic waste, and industrial activities. In addition to these factors, increased turbidity was caused by sand studio located at the upstream station and the $\mathrm{pH}$ was increased to a certain extent in the station number three. Moreover, in the study by Dadollahi et al. bad water quality of the Karoon River was due to entering sewage plant saponification (14). In Torabian et al. study, decline of water quality was due to building wastewater around the area in 2008-2009 (18). The classification of river water (Tajen River) by using the WQI showed that upstream stations had pure, clean, and healthy water and downstream stations had bad quality, which is similar to the result of this research (17). The water quality of the station number six was bad in all sampling months. The reason for this decline is discharge of industrial wastewater of the food factory near the river, discharge of untreated sewage bypass of Khorramabad municipal wastewater, and agricultural drainage around the river. Jafari et al. reported that the discharged municipal wastewater of treatment plant to the river not only reduces the quality of the water at the output station, but also affects the downstream stations (27). In addition, Mirzaei et al. stated that the entrance of urban and rural sewage discharge into the Jajrood River was the most important factor in the water pollution (28). In the study in Tarabanky rivers and canals Mahanady Taldana in Paradeep India in 2009, Samantray et al. claimed that Tarabanky water pollution was caused by human activities and industrial waste (29). Clayton identified the reduction in the water quality of Pearson due to discharge of water flowing lagoon and other environmental factors in 2009 (30). The study of Karoon River showed that the quality of water varies from good to medium (31). Tahmasebi et al. indicated that the quality of river water was medium and bad in all parts of the river (32).

In our study, the maximum ratio of EC and SAR were observed in station three, which was due to increased coarse sediment and depth of stony floor (Cretaceous limestone formations); it might also be due to carbonate rocks and sediments substances of the river substrate. Carbonate groups formed the rocks of Eocene and Oligocene periods of limestone; dolomites had formed the dolomitic limestone and dolomite lime. This type of rock with solubility in the water streams had important role in the formation of karst phenomena in the surface and depth. The mountains of this region have sedimentary origin and the scarcity of igneous rocks is one of the important characteristics of this area. In another study, Lalezari et al. concluded that the increased concentrations of the quality indexes in the southern plain can be attributed to the mineral solubility of limestone formations of shale and marl (33). Low flow in the water during months such as December causes increased EC and SAR; this increase is in proportion of a decrease in the concentration of calcium, magnesium, and sodium. Johnson et al. conducted a study in mountain streams of California and recognized an reverse association between the compression rate of calcium, magnesium, and sodium concentration and flow; the results obtained in this study are compatible and consistent with ours (34). Hardness of water is an important feature that helps preventing of the foam soap and increases the boiling point of water. The main cause of the hardness of the natural water is ions of calcium and magnesium. Khorramrood River of Khorramabad is like a spring with a high flow rate originating from the mountains surrounding the village of Rabat Nameki; the structure of mountains are carbonates and calcareous that cause relative increase in water hardness. It contributes to the EC. Increased hardness of the studied river water is influenced by geological structure of the studied basin. Rezaei Moghaddam et al. studied the travertine platform of Takht-e-Suleiman for the formation and evolution of channels made of limestone; they showed a high concentration of bicarbonate, calcium, and magnesium in the 
output water of the lake Takht Suleiman and stated that the exited constituent minerals were dissolved and had increased salts formation (35). EC is one of the most important parameters in determining the suitability of water for irrigation. Irrigation with high EC can increase the salt concentration of the soil and damage to agricultural land and crops because of its cumulative effect. High conductivity may rise through natural weathering of certain sedimentary rocks or may have an anthropogenic source, i.e. industrial and sewage effluent (36). The study of water quality in rivers showed two classes of $\mathrm{C} 1$ and $\mathrm{C} 2$ based on EC that indicates very low and medium salinity of the river, respectively. Reduced river flow during October and November due to low rainfall and low river discharge to water surface causes an increase in salts concentration of water and the result is increased EC and salinity. There is an inverse association between river flow and excited minerals in river and feeding of river from limestone springs in the months of low water, which led to high salinity of the river. Average SAR values measured at all studied stations during six months was less than one and was assigned to the S1 class. This suggests that the water sodium concentration was low. The distributions of points in the Wilcox diagram showed that the water quality at some stations was assigned to good class with medium salinity and low sodium (C2S1) and others were assigned to the C3S1 class with high salinity and low sodium. This indicates that the river water could be used for a variety of soils and crops. The soil aggregation of area should be irrigated by the average class water to prevent salinization of land and lower yields. Due to the inverse association between river flow and EC, EC increases in the dry season and decreases the water class for agriculture. The water quality of Jajrod river based on Wilcox index during low water months was assigned to $\mathrm{C} 2 \mathrm{~S} 1$ at Mamlou stations and in other months to C3S1 class. The results of the study were in agreement with our results (37). Tiri et al. in the assessment of river water quality in Algeria used Wilcox index; the results of the analysis showed a significant correlation of the EC with the concentration of sodium, calcium, and magnesium. Thus, water of that river was placed in C2S1 and C3S1 classes for agriculture, which were consistent with the results of the abovementioned study (24). Based on the results of the WQI index, we conclude that moving from the source of river towards the last station, the river water pollution was increased. Discharge of domestic sewage, industrial waste, animal waste, urban and rural rubbish, agricultural drainage, warm climate, low rainfall, and low river discharge during the study seasons were the main reasons for the reduction in water quality in the different sampling stations. According to Wilcox index, the geological structure of the studied basin was the main factor for the decline in the water quality for agricultural purposes.

\section{Acknowledgements}

This study was a part of a Master Degree thesis in Envi- ronmental Health Engineering Course of Mr. AbdolRahim Yusefzadeh (Code: 1336). Our special thanks goes to the moral and material support of Respectable Assistant of the Research Deputy of Lorestan University of Medical Sciences.

\section{Authors' Contributions}

Ghodratola Khoramabadi Shams Supervised the study; Hatam Godini and Edris Hoseinzadeh were advisors of the project; Abdolrahim Yusefzadeh performed the research and wrote the manuscript, collected and analyzed the data; Mohammad Khoshgoftar cooperated in writing the manuscript and analyzing the data.

\section{References}

1. Mahmud R, Inoue N, Sen R. Assessment of irrigation water quality by using principal component analysis in an arsenic affected area of Bangladesh. J Soil Nat. 2007;1(2):8-17.

2. Ackah M, Agyemang O, Anim AK, Osei J, Bentil NO, Kpattah L, et al. Assessment of groundwater quality for drinking and irrigation: the case study of Teiman-Oyarifa Community, Ga East Municipality, Ghana. Proc Int Acad Ecol Environ Sci. 2011;1(3-4):186-94.

3. Tiri A, Belkhiri L, Boudoukha A, Lahbari N. Characterization and evaluation of the factors affecting the geochemistry of surface water of Koudiat Medouar Basin, Algeria. Afr J Environ Sci Technol. 2011;5(5):355-62.

4. Sutharsiny A, Pathmarajah S, Thushyanthy M, Meththinka V. Characterization of Irrigation Water Quality of Chunnakam Aquifer in Jaffna Peninsula. Trop Agric Res. 2012;23(3):237-48.

5. Le Roux PAL, du Preez C, Strydom M, van Rensburg L, Bennie A. Effect of irrigation on soil salinity profiles along the Lower Vaal River, South Africa. Water SA J. 2007;33(4):473-8.

6. Shokuhi R, Hosinzadeh E, Roshanaei G, Alipour M, Hoseinzadeh S. Evaluation of Aydughmush dam reservoir water quality by National Sanitation Foundation Water Quality Index (NSFWQI) and water quality parameter changes. Iran J Health Environ. 2012;4(4):439-50.

7. Shokoohi R, Hoseinzadeh E, Alipour M, Hoseinzadeh S. Evaluation Aydughmush River Quality Parameters Changes and Wilcox index calculation. Rasayan J Chem. 2011;4(3):673-80.

8. Rahmani AR, Samadi MT. Water Quality Assessment of HamadanBahar Plain Rivers Using Wilcox Diagram for Irrigaton. Agric Biotechnol. 2008;9(2):13-27.

9. Sánchez E, Colmenarejo MF, Vicente J, Rubio A, García MG, Travieso L, et al. Use of the water quality index and dissolved oxygen deficit as simple indicators of watersheds pollution. Ecol Indic. 2007;7(2):315-28.

10. Bordalo AA, Nilsumranchit W, Chalermwat K. Water quality and uses of the Bangpakong River (eastern Thailand). Water Res. 2001:35(15):3635-42.

11. National Sanitation Foundation. Nitrates in Drinking Water. NSF 2012. Available from: http://www.Nsfconsumer.org.

12. Aenab AM, Singh SK, Al-Rubaye AAM. Nonpoint pollution of surface waters with phosphorus and nitrogen. Ecol Appl. 1998;4(7):523-7.

13. Gatot E, Sumiharni S. Proposing Water Quality Index Calculation Method for Indonesian Water Quality Monitoring Program. Int J Eng Sci. 2011;2(2):2086-3799.

14. Dadollahi Sohrab A, Arjmand F. Water quality index (WQI) Karun River as indicative of Effect saponification Khorramshahr wastewater. JOceanogr. 2010;1(4):21-7.

15. Yusefi Falkadhi A, Safdel H, Golparvar GH. Measurement of water quality in the drainage basin of Sefidrood in Gilan province; Third National Conference on Irrigation and Drainage Networks; Shahid Chamran University of Ahvaz. 2010

16. Hajian Nejad M, Rahsepar AR. Investigation of effect of city of Isfahan and effluent from Esfahan wastewater treatment plant on some of Zayandeh Rood river water quality parameters. Health 
Syst Res. 2010;9:821-8.

17. Ahmadi-Mamaqani Y, Khorasani N, Rafiee GH. Investigation of pollution sources and water quality of Tajan River. J Nat Environ. 2011;63(4):317-27.

18. Torabian A, Hashemi SH, Khalili. R, Ferdusi poor S. [Effects of harvesting on water quality in the river downstream of the dam Mamlu using QUAL2E model]. Environ Stud Fall. 2004;30(35):7669.

19. Sundaray SK, Nayak BB, Bhatta D. Environmental studies on river water quality with reference to suitability for agricultural purposes: Mahanadi river estuarine system, India-a case study. Environ Monit Assess. 2009;155(1-4):227-43.

20. Wikipedia. Lorestan Province. Wiki; 2012. Available from: http:/| www.wikipedia.org/wiki/LorestanProvince/.

21. Eaton A, Clesceri L, Rice W. Standard methods for the examination of water and waste water. 21th ed. Washington Dc: American Public Health Association; 2005.

22. Rezar M, Roshanfekri A, Ghorbani F. Evaluation of rivers water quality using water quality indices case study: Intervals Iydenk - Behbahan River Maron; Seventh International Seminar River Engineering; 2006; Shahid Chamran Ahvaz University. pp. 15-23.

23. Food and Agricultural Organization of the United Nations. Water quality for agriculture. Rom: FAO Irrigation and Drainage Paper; 1985. [updated 2014]. Available from: http://www.fao.org/DOCReP/003/T0234e/T0234e00.htm.

24. Tiri A, Boudoukha A. Hydrochemical analysis and assessment of surface water quality in koudiat medouar reservoir, Algeria. Eur J Sci Res. 2010;41(2):273-85.

25. Fuquan N, Guodong L, Jian Y, Huazhun R, Shangchun Y. ArcGISBased Rural Drinking Water Quality Health Risk Assessment. J Water Resource Prot. 2010;1:351-61.

26. Moghimi E. [River Eco-Geomorphology and Rights].Tehran: Tehran University Press; 2009.
27. Jafari SB, Nabibidhendi GR, Salemi A, Taherioon M, Ardestani M [Assessment Of Gheshlagh river water quality using water quality indices]. Environ Sci. 2009;6(4):19-28.

28. Mirzaei M, Nazari AR, Yari A. [Zonation Of Rever Jajrud]. J Ecol. 2005(37):17-25

29. Samantray P, Mishra BK, Panda CR, Rout SP. Assessment of water quality index in mahanadi and atharabanki rivers and Taldanda Canal in Paradip Area, India. J Hum Ecol. 2009;26(3):153-61.

30. Clayton M. Water Quality Analysis of Pearson Creek. Comparison of Pearson Creek Water Quality Since Discharge of Effluent Lagoon Water. Less Cheneaux Watershed Council. 2009. Available from: http://www.lescheneauxwatershed.org/downloads/claytons_report_pdf.pdf.

31. Safarian R, Mashayekhi N. Evaluation and classification of water quality of river Karoon (Zargan area, ommoltahir) and Comparison with the water quality index of River Maroon and Zohreh; Tenth National Conference on Environmental Health; Hamadan. 2007. pp. 23-35.

32. Tahmasebi S, Afkhami M, Takdastan A. [Study of Chemical, Physical and Microbial Quality of Gargar River, sw, Iran, Using NSF Water Quality Index]. Jundishapur J Health Sci. 2012;3(4):55-64.

33. Lalezari R, Tabatabaii SH. Shahrekord city Plain groundwater chemical characteristics. Ecol. 2010;36(53):8.

34. Johnson CM, Needham PR. Ionic composition of Sagehen Creek, California, following an adjacent fire. Ecol.1966;4(4):636-9.

35. Rezaei Moghaddam MH, Ghadri MR. Creation of self built limestone channels and their role on limestone. Geogr Environ Plan. 2010;21(2):1-16

36. Abdul Hameed M, Alobaidy J, Abid HS, Maulood KM. Application of water quality index for assessment of Dokan lake ecosystem, Kurdistan region, Iraq. J Water Resour Prot. 2010;2010: 792-8.

37. Zehtabian GH, Rafiei Emam A. Assessment of Jajrood river water quality on Varamin. Desert. 2003;8(2):164-77. 